\title{
PENGEMBANGAN PROSES UPGRADING MINYAK BATUBARA:

\author{
Pengaruh Temperatur, Tekanan dan Space Velocity
}

\author{
Yusnitati ${ }^{1)}$, Muhammad Hanif ${ }^{1)}$ dan M. Faizal ${ }^{2)}$ \\ ${ }^{1)}$ Pusat Teknologi Pengembangan Sumberdaya Energi \\ BPPT Gedung II Lantai 22 JI MH Thamrin 8 Jakarta 10340 \\ 2) Jurusan Teknik Kimia, Fakultas Teknik-UNSRI, Indragiri Hulu \\ E-mail: yusnitati@bppt.go.id; madhanif@kompascyber.com
}

\begin{abstract}
Minyak batubara cair dengan titik didih $70-360^{\circ} \mathrm{C}$, diperoleh dari proses pencairan batubara Tanito Harum menggunakan NEDOL Process skala pilot berkapasitas 150 ton/hari. Minyak batubara cair tersebut diupgrade untuk mengklarifikasi pengaruh temperatur reaksi, tekanan hidrogen, dan liquid hourly space velocity (LHSV) terhadap aktifitas hidrodenitrogenasi. Pengujian dilakukan dalam reactor fixed bed kontinyu berdiameter $8.5 \mathrm{~mm}$ menggunakan katalis $\mathrm{Ni}$ W/Alumina pada temperatur $300-375^{\circ} \mathrm{C}$, tekanan hidrogen 8-12 MPa, LHSV 0.75-3.0 $\mathrm{hr}^{-1}$ dan rasio hydrogen/oil $1000 \mathrm{NL} / \mathrm{L}$. Hasil pengujian menunjukkan bahwa aktifitas hidrodenitrogenasi meningkat dengan peningkatan temperatur reaksi dan tekanan hidrogen. Pada tekanan hidrogen $8 \mathrm{MPa}$, deaktifasi katalis terjadi lebih cepat dibandingkan dengan tekanan hydrogen $12 \mathrm{MPa}$ selama 15 hari waktu operasi. Selain itu, ditunjukkan pula bahwa pada operasi dengan LHSV yang lebih rendah dan tekanan hidrogen yang lebih tinggi akan lebih efektif untuk menurunkan atau menghilangkan senyawa nitrogen dalam proses upgrading minyak batubara cair. Sehingga, operasi pada tekanan hidrogen 12 MPa diharapkan dapat menghasilkan produk minyak batubara cair dengan kandungan nitrogen yang rendah untuk waktu operasi lebih dari satu tahun pada skala komersial.
\end{abstract}

Kata Kunci: hidrodenitrogenasi, katalis Ni-W/Alumina, minyak batubara cair, upgrading

\section{PENDAHULUAN}

Minyak bumi telah menjadi suatu sumber dominan untuk memenuhi kebutuhan energi, khususnya dalam sektor transportasi, sedangkan cadangan minyak bumi cenderung berkurang kuantitasnya seiring dengan peningkatan populasi dan pertumbuhan ekonomi. Oleh karena itu, implementasi teknologi pencairan langsung batubara peringkat rendah dapat menjadi salah satu alternatif teknologi untuk mengatasi masalah tersebut.

Proses upgrading minyak batubara cair merupakan aspek penting yang dapat menentukan kelayakan proses secara ekonomis pada teknologi pencairan langsung batubara peringkat rendah. Proses ini dapat terdiri dari hidrokracking, katalitik reforming, hidrogenasi dan penghilangan heteroatom seperti hidrodenitrogenasi, hidrodeoksigenasi atau hidrodesulfurisasi.
Minyak batubara cair mengandung senyawa nitrogen, oksigen, dan senyawa aromatis yang tinggi dengan kandungan sulfur yang rendah, sangat kontras dengan minyak bumi yang mengandung nitrogen yang rendah dengan kandungan sulfur yang tinggi. Kandungan elemen-elemen tersebut mengakibatkan terbentuknya gum/slugde yang dapat menganggu kestabilan minyak batubara cair pada saat penyimpanan dan dalam transportasinya. Selain itu, kandungan senyawa aromatis yang tinggi dapat menurunkan bilangan setana pada minyak batubara cair. Maka, proses upgrading minyak batubara cair lebih diarahkan pada proses hidrogenasi, hidrodenitrogenasi, hidrodeoksigenasi dan hidrokracking.

Di lain pihak, batasan lingkungan global mengenai kandungan heteroatom dan aromatis dalam bahan bakar semakin ketat untuk meminimalkan polusi udara seperti $\mathrm{NO}_{x}$ dan partikulat dari kendaraan bermotor. Sehingga 
penelitian dan pengembangan proses yang cocok untuk menghilangkan dan menurunkan senyawa aromatis mendapat perhatian khusus.

Beberapa penelitian telah dilakukan untuk mengembangkan proses peningkatan kualitas minyak batubara cair. [Shimada et. al.,1996; Mochida et.al.,1997] mengusulkan dua tahapan proses dalam upgrading minyak batubara cair. Dimana, tahap pertama adalah hidrogenasi, hidrodenitrogenasi dan hidrodeoksigenasi, sedangkan tahap kedua adalah hydrocracking dan hidrogenasi cincin aromatis. TCLC-NEDO, Jepang telah mengembangkan proses Conceptual Improved Brown Coal Liquefaction dengan Two-Stage Inline Hydrotreatment, untuk menghasilkan fraksi gasoline, kerosene dan diesel dari minyak batubara cair pada tingkat spesifikasi seperti fraksi minyak bumi. Pengembangan dan pengujian teknologi proses upgrading juga telah dikembangkan pada Process Development Unit (PDU) skala pilot berkapasitas 40 barel/hari di Funakawa, Jepang menggunakan umpan minyak batubara cair dari proses pencairan batubara Tanito Harum, Indonesia (NEDOL Process).

Kondisi reaksi untuk proses Improved $B C L$ dilakukan pada temperatur $330-350^{\circ} \mathrm{C}$ (firststage) dan $360-380^{\circ} \mathrm{C}$ (second-stage) dengan tekanan 14,7 MPa dan LHSV $1 \mathrm{hr}^{-1}$ untuk kedua tahap proses. Sedangkan, pada PDU skala pilot, operasi dilakukan pada temperatur $345^{\circ} \mathrm{C}$, tekanan $10 \mathrm{MPa}$ dan LHSV $0.4 \mathrm{hr}^{-1}$ untuk tahap awal hidrotreatment dan pada $345^{\circ} \mathrm{C}, 12 \mathrm{MPa}$, $0.4 \mathrm{hr}^{-1}$ untuk tahap kedua hidrotreatment. Selain itu, pada penelitian skala laboratorium menggunakan two-stage upgrading untuk middle dan heavy distilat, dilakukan pada temperatur 330-380 ${ }^{\circ} \mathrm{C}$, tekanan 6,9-11,8 MPa, LHSV 1-2 $\mathrm{hr}^{-1}$ (first-stage) dan pada $260-300^{\circ} \mathrm{C}, 6,9-11,8 \mathrm{MPa}$ dan 1-2 $\mathrm{hr}^{-1}$ (second-stage).

Tulisan ini membahas hasil penelitian pengaruh kondisi reaksi seperti temperatur, tekanan dan liquid hourly space velocity (LHSV) terhadap aktifitas penghilangan senyawa nitrogen dan sebagai salah satu upaya pengembangan proses upgrading minyak batubara cair pada skala komersial.

\section{BAHAN DAN METODE PENELITIAN}

\subsection{Minyak Batubara Cair}

Sampel minyak batubara cair diperoleh dari produk pencairan batubara Tanito Harum, Indonesia, pada pilot plant berkapasitas 150 ton/hari di Kashima, Jepang, yang merupakan campuran fraksi gas oil dan fraksi nafta minyak batubara cair dengan trayek titik didih $70-360^{\circ} \mathrm{C}$.
Karakteristik dari minyak batubara cair ditunjukkan pada Tabel 1.

Tabel 1. Karakteristik Minyak Batubara Cair (t.d. $70{ }^{\circ} \mathrm{C}-360^{\circ} \mathrm{C}$ )

\begin{tabular}{|l|r|}
\hline Analisis Elemen : & $\begin{array}{r}5.600 \mathrm{ppm} \\
340 \mathrm{ppm} \\
\text { Nitrogen } \\
\text { Sulfur } \\
\text { Oksigen }\end{array}$ \\
\hline \multicolumn{2}{|l}{ Komperat } \\
\hline \multicolumn{2}{|l}{} \\
\hline Fraksi Asam (phenol, & $15,5 \%$ berat \\
indanol) & $3 \%$ berat \\
Fraksi Basa (anilin, & $3,7 \%$ berat \\
quinolin, & $34,2 \%$ berat \\
benzoquinolin) & $16,9 \%$ berat \\
Fraksi Netral Polar & \\
(carbazol, indole) & \\
Monoaromatis (n-paraffin) & \\
Poliaromatis (naphthalin, & \\
pyrin) & \\
\hline
\end{tabular}

\subsection{Persiapan Katalis}

Katalis nickel-tungsten (Ni-W) berpenyangga alumina $\left(\mathrm{Al}_{2} \mathrm{O}_{3}\right)$ dengan komposisi $\mathrm{NiO} 4,2 \%$ berat, $\mathrm{WO}_{3} 29,2 \%$ berat dan luas permukaan $167 \mathrm{~m}^{2} / \mathrm{gr}$ dikalsinasi pada temperatur $400^{\circ} \mathrm{C}$ selama 2 jam. Selanjutnya, dilakukan proses sulfidasi di dalam image furnace dengan mengalirkan campuran gas $\mathrm{H}_{2} \mathrm{~S} / \mathrm{H}_{2}(10 \%$ vol, 80 $\mathrm{ml} / \mathrm{min}$ ) selama $1,5 \mathrm{jam}$ dari temperatur ruang sampai temperatur $400^{\circ} \mathrm{C}$ dan dipertahankan selama 2 jam pada temperatur $400^{\circ} \mathrm{C}$, kemudian didinginkan hingga temperatur ruang. Katalis yang telah mengalami proses sulfidasi ditempatkan dalam desikator untuk mencegah teroksidasi kembali oleh udara dan kemudian diisikan ke dalam reaktor.

Proses kalsinasi dilakukan untuk membentuk interaksi dan dispersi yang tinggi antara katalis $\mathrm{WO}_{3}$ dengan permukaan penyangga $\mathrm{Al}_{2} \mathrm{O}_{3}$, sehingga dapat meningkatkan kemampuan katalis untuk di sulfidasi (sulfidability). Sedangkan, proses sulfidasi dilakukan untuk membentuk phase aktif katalis sulfida.

\subsection{Metode Pengujian}

Pengujian pengaruh temperatur, tekanan dan LHSV pada upgrading minyak batubara cair dilakukan menggunakan reaktor fixed-bed sistem kontinyu dengan diameter dalam $8.5 \mathrm{~mm}$ dan panjang $450 \mathrm{~mm}$. Skema peralatan pengujian ditunjukkan pada Gambar 1.

Pada kondisi tidak tunak (unsteady state), umpan minyak batubara cair di dalam tangki dipompa dengan kecepatan aliran $0.1 \mathrm{ml} / \mathrm{min} \mathrm{ke}$ dalam reaktor yang telah terisi oleh katalis $\mathrm{Ni}$ W/Alumina tersulfidasi sebanyak $3 \mathrm{gram}$ dan packing bola alumina (diam. $2 \mathrm{~mm}$ ). Gas hidrogen diinjeksi ke dalam reaktor dengan 
kecepatan aliran $100 \mathrm{ml} / \mathrm{min}$ (rasio hidrogen/minyak = $1000 \mathrm{NL} / \mathrm{L}$ dan LHSV 1,5 $\mathrm{hr}^{-1}$ ). Kemudian, dilakukan uji kebocoran selama 1 jam menggunakan hydrogen gas detector pada tekanan reaksi $12 \mathrm{MPa}$. Jika tidak terjadi kebocoran, timbangan umpan diset pada posisi nol dan temperatur pemanas dinaikkan sampai $180{ }^{\circ} \mathrm{C}$ dan dipertahankan selama 2 jam dengan injeksi gas nitrogen ke tangki umpan untuk mencegah bubling udara. Selanjutnya, dari temperatur $180{ }^{\circ} \mathrm{C}$ dinaikkan lagi sampai $265^{\circ} \mathrm{C}$ dan dipertahankan selama 2 jam.

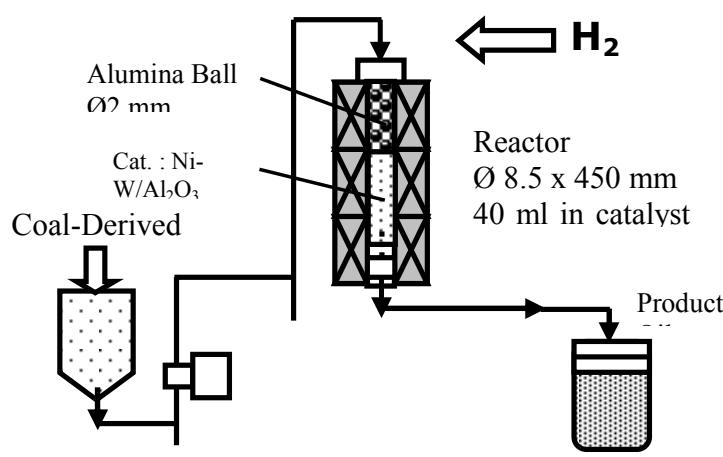

Gambar 1. Skema peralatan fixed-bed reaktor

Setelah mencapai kondisi tunak (steady state), maka kondisi operasi diset sesuai dengan kondisi pengujian. Pada pengujian awal temperatur reaksi dinaikkan secara bertahap pada $300,325,350$ dan $375^{\circ} \mathrm{C}$ dengan LHSV 1.5 $\mathrm{hr}^{-1}$, tekanan gas hidrogen 8 dan $12 \mathrm{MPa}$ untuk masing-masing temperatur pengujian. Selanjutnya, pengujian dilakukan pada LHSV 0,$75 ; 1,5$ dan $3 \mathrm{hr}^{-1}$ dengan tekanan $8 \mathrm{MPa}$ selama 10 hari operasi dan $12 \mathrm{MPa}$ selama 15 hari operasi. Pengaruh temperatur, tekanan dan LHSV dievaluasi terhadap kandungan nitrogen dalam produk minyak batubara cair.

\subsection{Metode Analisis}

Sebelum analisis, $\mathrm{Na}_{2} \mathrm{SO}_{4}$ ditambahkan ke dalam produk minyak dan di aliri gas nitrogen untuk menghilangkan air dan ammonia. Kandungan nitrogen pada umpan dan produk minyak batubara cair dianalisa menggunakan APS 35 Elemental Analyzer yang dilengkapi electrochemical detector.

\section{Hasil Penelitian Dan Diskusi}

\subsection{Pengaruh temperatur reaksi dan tekanan hidrogen}

Gambar 2 menunjukkan pengaruh temperatur reaksi dari $300-375^{\circ} \mathrm{C}$ pada tekanan hidrogen 8 dan $12 \mathrm{MPa}$ terhadap aktifitas hidrodenitrogenasi dengan LHSV 1,5 $\mathrm{hr}^{-1}$.

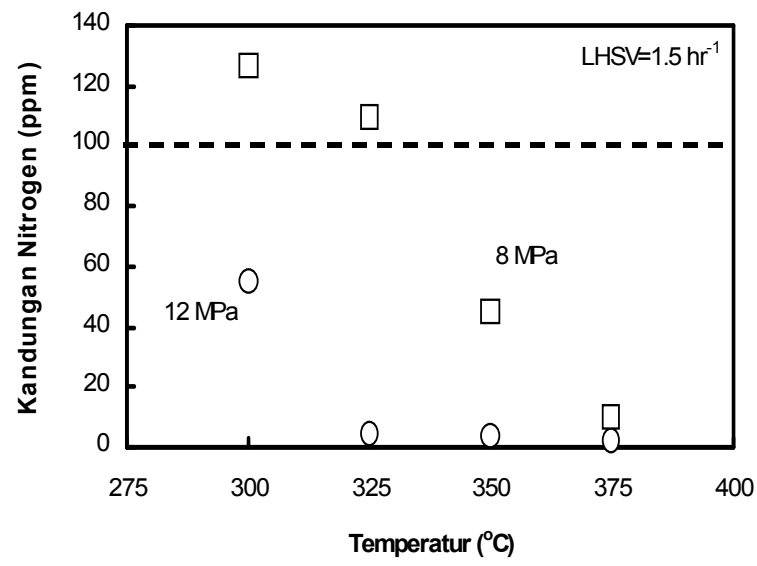

Gambar 2. Pengaruh temperatur reaksi dan tekanan hidrogen terhadap kandungan nitrogen

Kandungan nitrogen mengalami penurunan seiring dengan kenaikan temperatur reaksi. Pada temperatur $300^{\circ} \mathrm{C}$ dan tekanan $12 \mathrm{MPa}$, diperoleh kandungan nitrogen sekitar 56 ppm. Sedangkan pada temperatur yang sama untuk tekanan $8 \mathrm{MPa}$, diperoleh kandungan nitrogen di atas $100 \mathrm{ppm}$. Pada temperatur $325^{\circ} \mathrm{C}$ dan tekanan $12 \mathrm{MPa}$, telah berhasil menurunkan kandungan nitrogen hingga di bawah $10 \mathrm{ppm}$. Sementara itu, pada tekanan $8 \mathrm{MPa}, 325^{\circ} \mathrm{C}$, kandungan nitrogen masih di atas $100 \mathrm{ppm}$. Selanjutnya, pada temperatur reaksi $350^{\circ} \mathrm{C}$, tekanan $12 \mathrm{MPa}$, diperoleh penurunan kandungan nitrogen yang tidak begitu signifikan dengan temperatur $325^{\circ} \mathrm{C}, 12 \mathrm{MPa}$. Untuk operasi dengan tekanan $8 \mathrm{MPa}$ pada temperatur yang sama, diperoleh kandungan nitrogen sekitar 45 ppm. Pada temperatur reaksi $375^{\circ} \mathrm{C}$, kandungan nitrogen di bawah 10 ppm untuk kedua tekanan hidrogen 8 dan $12 \mathrm{MPa}$, tetapi pada tekanan $12 \mathrm{MPa}$ diperoleh kandungan nitrogen yang lebih rendah.

Secara umum dapat disimpulkan bahwa semakin tinggi temperatur reaksi dan tekanan hidrogen, maka aktifitas hidrodenitrogenasi juga meningkat. Hal ini ditunjukkan dengan kandungan nitrogen terendah yang diperoleh pada temperatur $375^{\circ} \mathrm{C}$ dan tekanan $12 \mathrm{MPa}$.

Dalam beberapa literature dijelaskan bahwa ada hubungan tidak linear (non-linearity) antara aktifitas atau konversi hidrodenitrogenasi dengan temperatur reaksi, seperti ditunjukkan pada Gambar 1. Hal ini mengindikasikan terjadinya keterbatasan kesetimbangan dalam reaksi. [Katti, et.al, 1988; Broderick,et.al, 1981;] melaporkan bahwa temperatur dapat memberikan pengaruh yang kuat terhadap kecepatan relatif hidrogenasi dan hidrogenolisis. Dimana, kenaikan temperatur akan meningkatkan kecepatan hidrogenasi secara tajam. [Krishnamurthy, et. al., [1981] juga 
menjelaskan bahwa pengaruh temperatur berhubungan erat dengan kesetimbangan termodinamika. Sugimoto dan Hanif [Sugimoto, Y., Hanif M., 2000] melaporkan bahwa terjadi peningkatan aktifitas katalis dengan adanya kenaikan temperatur reaksi pada percobaan di dalam reaktor kontinyu menggunakan katalis $\mathrm{Ni}$ W/Alumina.

Hubungan tersebut menunjukkan pula bahwa pada tekanan $12 \mathrm{MPa}$ akan diperoleh aktifitas hidrodenitrogenasi yang lebih tinggi dibandingkan pada tekanan $8 \mathrm{MPa}$. Walaupun operasi pada tekanan hidrogen yang rendah lebih ekonomis, namun deaktifasi katalis akan lebih cepat terjadi pada tekanan yang rendah, dalam kasus ini pada tekanan $8 \mathrm{MPa}$.

Untuk menginvestigasi pengaruh tekanan hidrogen secara lebih detail, maka dilakukan pengujian dengan variasi LHSV dalam waktu operasi yang lebih lama, seperti didiskusikan pada hasil penelitian di bawah ini.

\subsection{Pengaruh LHSV dan tekanan hidrogen}

Gambar 3 menunjukkan pengaruh LHSV 0,75; 1,5; $3 \mathrm{hr}^{-1}$ pada tekanan 8 dan $12 \mathrm{MPa}$ terhadap aktifitas hidrodenitrogenasi dengan temperatur reaksi $375^{\circ} \mathrm{C}$ selama 10 hari dan 15 hari operasi.
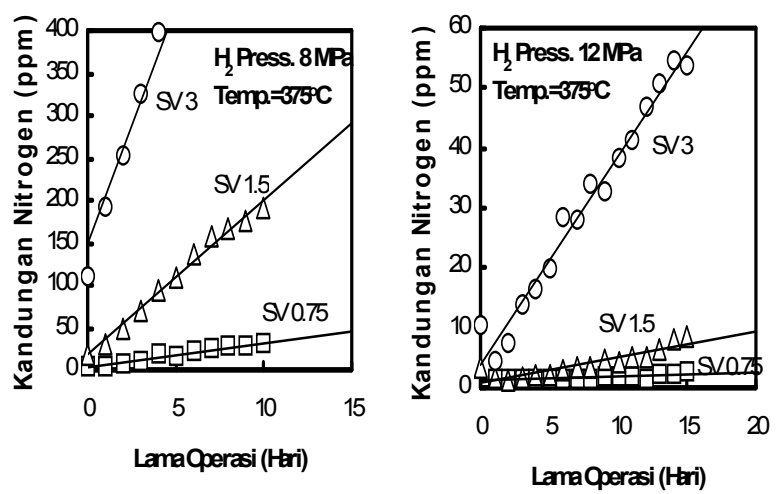

$\begin{array}{cl}\text { Gambar 3. } & \begin{array}{l}\text { Pengaruh LHSV dan tekanan } \\ \text { terhadap kandungan nitrogen } \\ \text { pada produk minyak }\end{array}\end{array}$

Sesuai dengan hasil penelitian di atas, maka pengujian ini dilakukan pada temperatur $375^{\circ} \mathrm{C}$ yang telah menunjukkan aktifitas hidrodenitrogenasi yang lebih tinggi. Hasil pengujian menunjukkan bahwa pada tekanan 8 MPa dan LHSV $3 \mathrm{hr}^{-1}$ terjadi penurunan aktifitas hidrodenitrogenasi atau deaktifasi katalis yang lebih cepat dibandingkan dengan LHSV 1,5 dan $0,75 \mathrm{hr}^{-1}$. Tahap awal operasi pada LHSV 3 , kandungan nitrogen sekitar 100 ppm dan selanjutnya meningkat secara drastis. Pada LHSV 1,5, terjadi kenaikan kandungan nitrogen secara bertahap selama operasi dari $5 \mathrm{ppm}$ hingga 180 ppm. Sedangkan, pada LHSV 0,75, kandungan nitrogen pada produk minyak relatif stabil sekitar $20 \mathrm{ppm}$ selama 10 hari waktu operasi. Selanjutnya, hasil pengujian variasi LHSV pada tekanan $12 \mathrm{MPa}$ menunjukkan aktifitas hidrodenitrogenasi yang lebih tinggi dibandingkan pada tekanan $8 \mathrm{MPa}$, terutama dengan LHSV 3 dan $1,5 \mathrm{hr}^{-1}$ selama 15 hari operasi. Sedangkan pada LHSV 0,75 menghasilkan kandungan nitrogen yang relatif stabil sekitar 1-3 ppm.

Oleh karena itu dapat disimpulkan bahwa pada tekanan $12 \mathrm{MPa}$ dan LHSV 0,75 memberikan aktifitas hidrodenitrogenasi yang lebih tinggi. Hal ini didukung oleh pengujian yang dilakukan oleh [Sato, et.al, 1997] dan [Rollman, et. al, 1977] yang melaporkan bahwa pada LHSV yang lebih rendah dan tekanan hidrogen yang lebih tinggi akan lebih efektif dalam proses hidrogenasi, hidrodenitrogenasi dan hidrodeoksigenasi dibandingkan pada temperatur yang lebih tinggi hingga $390^{\circ} \mathrm{C}$.

Untuk memperjelas perbandingan antara tekanan hidrogen 8 dan $12 \mathrm{MPa}$, maka diplot hubungan seperti ditunjukkan pada Gambar 4.

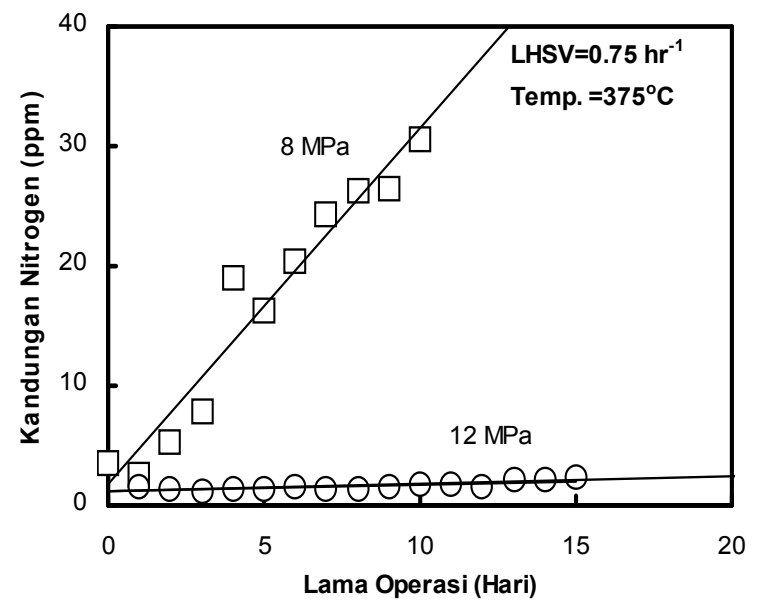

Gambar 4. Perbandingan tekanan hidrogen 8 dan $12 \mathrm{MPa}$ terhadap kandungan nitrogen

Hubungan ini menunjukkan dengan jelas bahwa ketika sample minyak batubara cair dengan kandungan nitrogen 5200 ppm di hidrogenasi pada temperatur $375^{\circ} \mathrm{C}$, LHSV 0,75 $\mathrm{hr}^{-1}$ dan tekanan $12 \mathrm{MPa}$, kandungan nitrogen di dalam produk minyak batubara cair telah dapat diturunkan hingga 1-3 ppm selama 15 hari waktu operasi. Konversi hidrodenitrogenasi diperoleh lebih dari $99,9 \%$. Oleh karena itu, operasi pada tekanan hidrogen $12 \mathrm{MPa}$ diharapkan dapat menghasilkan produk minyak batubara cair dengan kandungan nitrogen yang rendah untuk 
waktu operasi lebih dari satu tahun. Sehingga, keseluruhan hasil pengujian ini dapat dijadikan rekomendasi untuk kondisi operasi pada skala komersial.

\section{KESIMPULAN}

Secara umum dapat disimpulkan bahwa aktifitas hidrodenitrogenasi meningkat dengan peningkatan temperatur reaksi dan tekanan hidrogen. Hal ini ditunjukkan bahwa pada tekanan hidrogen $8 \mathrm{MPa}$, deaktifasi katalis terjadi lebih cepat dibandingkan dengan tekanan hydrogen $12 \mathrm{MPa}$ selama 15 hari waktu operasi.

Selain itu, ditunjukkan pula bahwa pada operasi dengan LHSV yang lebih rendah dan tekanan hidrogen yang lebih tinggi akan lebih efektif untuk menurunkan atau menghilangkan senyawa nitrogen dalam proses upgrading minyak batubara cair.

Dengan demikian operasi pada tekanan hidrogen $12 \mathrm{MPa}$ diharapkan dapat menghasilkan produk minyak batubara cair dengan kandungan nitrogen yang rendah untuk waktu operasi lebih dari satu tahun pada skala komersial.

\section{DAFTAR PUSTAKA}

Broderick D.H., Gates, B.C., 1981. AlChE Journal, July 1981, 27, 4, 663-673.

Katti S at. al., Ind. Eng. Chem. Process, 1988., $27,10$.

Krishnamurthy S., et. al., 1981. AlChe E. Journal, 27, (1981), 994-1001.

Mochida, M., $1997 . \quad$ Improvement of Hydrodenitrogenation in Co-refining of CoalDerived Liquid and Petroleum Fraction. Sekiyu Gakkaishi, 40, hal. 393-399.

Rollman L.D., 1977. Journal of Catalysis. 46, 1977, 243-252.

Sato Y., 1997. Catalysis Today. 39, 1997, 89-98.

Shimada, H., dkk., 1996. Recent Development of Coal Liquid Upgrading Catalysts, Japan-US Joint Meeting, Pittsburgh, USA.

Sugimoto, Y. dan Hanif, M., 2000. Upgrading of Coal-Derived Liquid over Ni-W/Alumina. Japan Institute of Energy, hal. 65-68. 